\title{
Riboflavin removal by commercial bentonites and charcoals in white and red wines
}

\author{
Veronica Vendramin ${ }^{1,2}$, Simona Primerano ${ }^{1,3}$, Giampiero Leserri $^{2}$, Giulio Paniccia ${ }^{2}$, Simone Vincenzi ${ }^{1,3 *}$ \\ ${ }^{1}$ Centre for Research in Viticulture and Enology (CIRVE), University of Padova, Viale XXVIII Aprile 14, 31015 \\ Conegliano (TV), Italy; ${ }^{2}$ Department of Land, Environment, Agriculture and Forestry (LEAF), University of Padova, \\ Viale dell'Università 16, 35020 Legnaro (PD), Italy; ${ }^{3}$ Department of Agronomy, Food, Natural Resources, Animals and \\ Environment (DAFNAE), University of Padova, Viale dell'Università 16, 35020 Legnaro (PD), Italy
}

*Corresponding Author: Centre for Research in Viticulture and Enology (CIRVE), University of Padova, Viale XXVIII Aprile 14, 31015 Conegliano (TV), Italy. Email: simone.vincenzi@unipd.it

Received: 19 August 2020; Accepted: 26 February 2021; Published: 1 April 2021

(c) 2021 Codon Publications

OPEN ACCESS (C) (i) (ㄱ)

PAPER

\begin{abstract}
Riboflavin (RF) represents one of the primary molecules undergoing photodegradation in wine, and its excited form acts as an intermediate in light-induced oxidation reactions responsible for the light-struck fault. A recent study has revealed bentonites (BENs) and charcoals (CHAs) as the most promising fining agents for removal of RF in model wine. This work explored their potential on both white and red wines, where polyphenols could interfere in the fining agent-RF interaction. A total of 11 BENs and 11 CHAs were compared. BENs exhibited a limited capacity, while decoloring carbons confirmed a great attitude for removal of RF in white wine, even at low dosages. Nevertheless, efficiency of CHAs shows a sensible reduction in red wine.
\end{abstract}

Keywords: bentonite, charcoal, red wine, riboflavin removal, white wine

\section{Introduction}

Shelf life of wine assumes a complicated meaning because of high diversity in both wine styles and typical characters searched by consumers. The quality of final product depends on both winemaking practices (fermentation and post-fermentation fining treatments) and storage in bottles. Maturation of wine should be strictly controlled to avoid undesirable chemical reactions, with particular attention to temperature and light conditions during transportation to the final seller and its often long storage. The post-fermentation is particularly critical for red wine because it commonly requires more time for maturation. Exposure to light could have two independent effects on wine: first, it could activate oxidative reactions, and second, it could cause heat-induced damages on direct exposure to sunlight (Jackson, 2011). In order to limit light-induced oxidation, the best protection is represented by storage in dark conditions and use of ultraviolet (UV)-masking bottles. It is known that green glass bottles can filter a larger spectrum of UV-Visible (VIS) wavelengths than uncolored bottles, thus reducing the rate of photodegradation reactions (Grant-Preece et al., 2017). However, this technological requirement is in contrast with the consumer preference for uncolored bottles, which is rapidly growing along with market for rosè wines. Riboflavin (RF) assumes a particular relevance in wine's shelf life because of its implication in intermolecular photoreduction. In fact, RF is one of the principal responsible for the development of light-struck taste, a wine fault characterized by 'cooked-cabbage' aroma. RF is thermostable at the temperature of winemaking process, but it is highly photosensitive and can easily undergo photochemical degradation (Sheraz et al., 2014). In aqueous solutions, RF is implicated in photosensitization reaction that acts following two mechanisms. The type 1 pathway results in the formation of two charged free radicals, RF and a 
target molecule, through hydrogen- or electron-transfer reactions between the excited triplet state of $R F\left({ }^{3} R F_{1}\right)$ and the substrate. When this substrate is methionine (Met), it leads to the formation of methional. While RF radical is involved in a recycling reaction, methional is unstable, and thus readily decomposes to methanethiol $(\mathrm{MeSH})$ and acrolein. In addition, two molecules of methional can combine into dimethyl disulfide (DMDS). The type 2 process uses the energy transferred from ${ }^{3} \mathrm{RF}_{1}$ to oxygen to form singlet oxygen, which can then react with multiple biological substrates. In light-struck reactions, it oxidizes methionine sulfur, generating methionine sulfoxide (Silva et al., 2019). MeSH and DMDS are the main compounds responsible for the 'cookedcabbage' aroma of light-struck reaction; they have a perception threshold of $2-10 \mu \mathrm{g} / \mathrm{L}$ and $20-45 \mu \mathrm{g} / \mathrm{L}$, respectively (Fracassetti et al., 2019). In a recent study, Fracassetti and colleagues (2019) explored the relationship between Met and RF and verified that Met degradation could be avoided if RF concentration remains below $50 \mu \mathrm{g} / \mathrm{L}$. In a different study, the same authors compared different fining agents with the aim to determine the clarification practice that could be the most efficient one for removal or lowering of RF (Fracassetti et al., 2017). This study compared several fining agents, namely polyvinylpolypyrrolidone (PVPP), bentonite (BEN), zeolite, silica, kaolin, albumin, and charcoal (CHA), using different concentrations in model wine, and identified BEN and $\mathrm{CHA}$ as the most promising agents. However, the efficacy of fining agents seems strictly dependent on the media composition, as demonstrated by comparison of $\mathrm{BEN}, \mathrm{CHA}$, and zeolite performance in both model wine and a real Chardonnay wine (Fracassetti et al., 2017). In this case, the CHA removal efficacy was lower in real wine at all the tested dosages. From the applicative point of view, it would be interesting to understand whether different categories of BENs and CHAs could be used successfully in real wines. Besides white wines, which are commonly preferred for RF studies because of being more subjected to light-struck fault, red wines represent an interesting case of study because, as reported by Lagunes et al. (2017), their extracts could act as photosensitizer if exposed to light, generating ${ }^{1} \mathrm{O}_{2}$, which in turn is able to oxidize other compounds. Moreover, polyphenols make more complex the removal of RF because of the high affinity of phenols to CHAs (Lisanti et al., 2017). A fine balance between the quenching and the photosensitizing nature of red wine polyphenols is of particular interest for monitoring the removal of $\mathrm{RF}$ in this kind of wine. In the present study, different commercial BENs and CHAs, provided by different suppliers, were compared in two wines to explore deeply their ability to remove RF. In particular, it was verified whether this ability is correlated to other fining properties, such as protein removal and decolorizing (DEC) capacity.

\section{Materials and methods}

\section{Chemicals and reagents}

Methanol, trifluoroacetic acid (TFA), tartaric acid, acetic acid, and sodium acetate were purchased from SigmaAldrich (Milano, Italy). Enocyanin powder (Enocianina GSE12 UC) was provided by EVER S.R.L. (Pramaggiore, Italy). Water of HPLC grade was obtained from Milli-Q system (Millipore Filter, Bedford, MA, USA).

\section{Bentonites and charcoals}

Eleven BENs, two calcic (CAL), one sodic-calcic (SODCAL), and eight sodic (SOD), and $11 \mathrm{CHAs}$, four deodorizing (DEO) and seven DEC, were provided by different commercial suppliers.

\section{Wine selection}

The wines were selected from different wine samples for their medium-high RF content. One white wine (Glera base wine, harvest 2018, produced by School of Oenology Cerletti, Conegliano (TV), Italy), with a content of $123.9 \mu \mathrm{g} / \mathrm{L}$ of RF, was chosen for BEN trials. This wine showed $9.6 \%$ alcohol and $6.5 \mathrm{~g} / \mathrm{L}$ of titratable acidity. One white wine (Glera base wine) and another red wine (Wildbacher), both produced by Collalto winery (Susegana (TV), Italy), with $104.0 \mu \mathrm{g} / \mathrm{L}$ and $138.6 \mu \mathrm{g} / \mathrm{L}$ of RF, respectively, were chosen for $\mathrm{CHA}$ treatments. Glera wine (harvest 2018) showed 11.6\% alcohol and 6.2 $\mathrm{g} / \mathrm{L}$ of titratable acidity, while Wildbacher (harvest 2018) showed $12.5 \%$ alcohol and $5.1 \mathrm{~g} / \mathrm{L}$ of titratable acidity.

\section{Bentonite's protein adsorption trial}

Deproteinization capability of BENs was evaluated according to modified Oeno 441-2011 Resolution (The International Organization of Vine and Wine [OIV], 2011). Trial solution was prepared using bovine serum albumin protein (BSA) $500 \mathrm{mg} / \mathrm{L}$ instead of ovalbumin $5 \mathrm{~g} / \mathrm{L}$, and the protein was dissolved into model wine $(5 \mathrm{~g} / \mathrm{L}$ tartaric acid, $12 \% \mathrm{v} / \mathrm{v}$ ethanol, $\mathrm{pH}=3$ ), whereas in the OIV method, the ethanol was absent. Eight BEN dosages (namely 10, 20, $30,40,50,60,70,80 \mathrm{~g} / \mathrm{hL}$ ) were tested in order to determinate BEN adsorption curves. Samples were shaken and maintained in dark at $25^{\circ} \mathrm{C}$ for 30 min before performing protein quantification using a Pierce BCA Protein Assay Kit (Fischer Scientific Italia, Rodano (MI), Italy). After an incubation of $30 \mathrm{~min}$ at $37^{\circ} \mathrm{C}$, samples were read using Microplate Reader (Euroclone) and data were elaborated by Software Manta and quantified over a calibration curve of BSA between $12.5 \mathrm{mg} / \mathrm{L}$ and $1000 \mathrm{mg} / \mathrm{L}$. 


\section{Charcoal's decolorization power in enocyanin solution}

Decolorizing power (DP) of a commercial CHA was evaluated applying the method reported in OIV 7/2007 (OIV, 2007) with little modifications. The enocyanin solution was prepared adding $4.5 \mathrm{~g} / \mathrm{L}$ of enocyanin, $7 \mathrm{~g} / \mathrm{L}$ of tartaric acid, $4 \mathrm{~g} / \mathrm{L}$ of acetic acid, and $7 \mathrm{~g} / \mathrm{L}$ of sodium acetate. The solution was stirred to allow complete dissolution and centrifuged for $10 \mathrm{~min}$ at 14,000 g. Supernatant was recovered and its absorbance was read in quartz cuvettes (2-mm path length) at three different wavelengths, namely 420, 520, $620 \mathrm{~nm}$, using spectrophotometer ULTROSPEC 2100pro (Amersham Bioscience Europe $\mathrm{GmbH}$, Cologno Monzese (MI), Italy). The color intensity (CI) was calculated as the sum of the three absorbance values standardized to a length path of $10 \mathrm{~mm}$. Each CHA was added to 100 $\mathrm{mL}$ of enocyanin solution at a final concentration of 1 $\mathrm{g} / \mathrm{L}$. Samples were stirred for $30 \mathrm{~min}$; after $10 \mathrm{~min}$, they were collected into Eppendorf tubes and centrifuged for $10 \mathrm{~min}$ at $14,000 \mathrm{~g}$ to remove CHAs. Supernatant CI was measured as described for enocyanin solution. Finally, DP was expressed as percentage using the following equation:

$$
\mathrm{DP}=100 \times \frac{\mathrm{CI} 1-\mathrm{CI} 2}{\mathrm{CI} 1},
$$

where CI1 is the enocyanin solution color intensity and $\mathrm{CI} 2$ is its color intensity after CHA treatment. The specific DP of each CHA was calculated by three independent replications.

\section{Bentonites and charcoals riboflavin removal in wine}

Four BEN dosages were chosen for removal of RF in white wine (Glera wine with $123.9 \mu \mathrm{g} / \mathrm{L}$ of RF), namely 20, 40, 60 , and $80 \mathrm{~g} / \mathrm{hL}$; the experiment was performed twice in 50-mL Falcon tubes. Tubes were vigorously shaken to allow dispersion of BEN and maintained at $25^{\circ} \mathrm{C}$ for $10 \mathrm{~min}$ before centrifugation at $14,000 \mathrm{~g}$ for $10 \mathrm{~min}$. Removal assay was repeated in two independent tests. For CHAs, five dosages were selected for both red and white wines (Wildbacher and Glera, with $138.6 \mu \mathrm{g} / \mathrm{L}$ and $104 \mu \mathrm{g} / \mathrm{L}$ of RF, respectively), namely $10,5,2,1$, and $0.5 \mathrm{~g} /$ $\mathrm{hL}$. The test was repeated for three times. Samples were shaken and kept in dark for $24 \mathrm{~h}$. At the end of time contact, samples were mixed and centrifuged for $10 \mathrm{~min}$ at $14,000 \mathrm{~g}$ in order to assure removal of CHA. The supernatant obtained was used for both RF quantification and color intensity determination. For the latter analysis, control CI (CC) and samples CI (CS) were used in Eq. (1) in place of $\mathrm{CI} 1$ and $\mathrm{CI} 2$, respectively. Color intensity was calculated as 420-nm absorbance value for the white wine and sum of the 420,520, and $620 \mathrm{~nm}$ absorbance values for the red wine.

\section{Quantification of riboflavin in high-performance liquid chromatography (HPLC)}

A Nexera HPLC system (Shimadzu) equipped with RF 20-A XS fluorescence detector was used. Filtered samples $(20 \mu \mathrm{L})$ were separated in a Kinetex C18 $(5 \mu \mathrm{m}$, $100 \AA$, $150 \times 4.6 \mathrm{~mm}$ Phenomenex). Eluting solvents were as follows: (A) Milli-Q water and $0.1 \%$ of TFA v/v and (B) gradient-grade methanol and $0.1 \%$ of TFA $v / v$. The gradient program was $0-2 \mathrm{~min}, 30 \% \mathrm{~B} ; 2-10 \mathrm{~min}$, 30-60\% B; 10-11 min, 60-100\% B; 11-14 min, 100\% B; 14-15 min, $100-30 \% \mathrm{~B}$; and $15-18 \mathrm{~min}, 30 \% \mathrm{~B}$. The flow rate was set to $0.6 \mathrm{~mL} / \mathrm{min}$ and the column temperature was kept at $37^{\circ} \mathrm{C}$. The RF was detected by fluorescence using 452 and $516 \mathrm{~nm}$ as excitation and emission wavelengths, respectively. RF was quantified using the external standard method. Data were acquired and processed with LabSolutions version 5.93.

\section{Statistical analyses}

$R$ software ( $R$ version 3.0.1) was used for statistical analysis. Differences were evaluated by one-way ANOVA, Welch's ANOVA, and Kruskal-Wallis $\mathrm{H}$ test depending on data distribution. Post hoc analyses Tukey HSD test and Games-Howell test were used for ANOVA and Welch's ANOVA, respectively, while Dunn test with Holm correction was chosen as Kruskal-Wallis post hoc test. Correlations were tested using Pearson's correlation test. Statistical significance was attributed with $P<0.05$ or a Confidence Interval of 0.95 .

\section{Results and discussion}

\section{Bentonite's deproteinization capacity}

Bentonites are mainly used to remove proteins and avoid unpleasant haze in white wines. Selected BENs have been characterized for determining their performance in protein removal using modified Oeno 11/2003 (OIV, 2011) protocol. For this purpose BSA was considered more suitable than egg albumin because of its isoelectric point and absence of glycosylation, which make BSA more similar to wine proteins (Sarmento et al., 2000). In addition, $12 \%$ ethanol was added to the test solution, as BEN is generally used in wine and it has been demonstrated that ethanol can influence the swelling of BEN, modifying its protein removal ability (Achaerandio et al., 2001). Moreover, the quantity of protein used was $500 \mathrm{mg} / \mathrm{L}$, more close to the real protein content in unstable white 
Table 1. Summary of selected bentonites. For each bentonite, de-proteinization curve slope and related $R^{2}$ values are reported.

\begin{tabular}{llll} 
Sample ID & Category & Slope & $\boldsymbol{R}^{2}$ \\
\hline BENT1 & SOD & 7.97 & 0.99 \\
BENT2 & SOD & 7.17 & 0.99 \\
BENT3 & CAL & 4.11 & 1.00 \\
BENT4 & CAL & 2.44 & 0.94 \\
BENT5 & SOD-CAL & 2.61 & 0.94 \\
BENT6 & SOD & 6.75 & 0.96 \\
BENT7 & SOD & 5.34 & 0.97 \\
BENT8 & SOD & 5.30 & 0.97 \\
BENT9 & SOD & 7.00 & 0.99 \\
BENT10 & SOD & 4.99 & 1.00 \\
BENT11 & SOD & 7.14 & 0.99 \\
\hline
\end{tabular}

wines (Marangon et al., 2011) than the 5-g/L of ovalbumin used in the original OIV method.

Removal curve slopes of 11 BENs belonging to CAL, SOD, and SOD-CAL categories were used to compare efficiency of BENs, the highest slope value corresponded to the best performing BEN. Data revealed a positive linear relationship between BEN dosage and quantity of protein removed in this range of concentration. Only in two cases, namely BENT4 and BENT5, $R^{2}$ was lower than 0.95 (Table 1) because of the lower absorbing capacity of these BENs. Statistical analyses revealed a significant difference between categories $\left(F_{(2,8)}=10.5, P<0.05\right)$ and post hoc test-grouped SOD-CAL with CAL being the reason of their low deproteinization capacity (Figure 1).

This trend is in accordance with Jönsson et al.'s (2009) findings, which demonstrated that SOD bentonites are characterized by about 10 times major swelling capability than CAL ones. The nature of cations arranged between

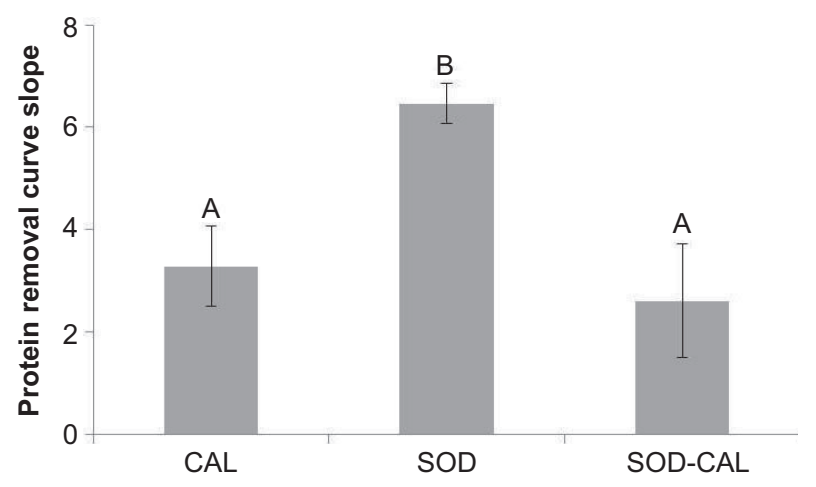

Figure 1. Slope index of protein removal curves. Leastsquare mean values and standard errors are presented. Different capital letters identify significantly different groups $(P<0.05)$ according to Tukey test. montmorillonite lamellae strongly affects physical properties of BEN, resulting in a great difference in protein-binding ability. Sodium guarantees a major distance between BEN layers enhancing protein entrance and a higher availability of binding surfaces.

\section{Bentonite's effect on removal of riboflavin}

Attitude of BEN to removal of RF was recently studied in comparison to other fining agents (Fracassetti et al., 2017). BEN was identified as one of the most useful fining agents. In fact, in the study conducted by Fracassetti et al. (2017), all the tested BENs (six, all from the same supplier) were able to remove about $60 \%$ of original RF in an RF-enriched model wine $(350 \mu \mathrm{g} / \mathrm{L}$ of $\mathrm{RF})$. For the screening presented in this work, BENs were chosen with the aim to explore a major variability of commercial products, and therefore 11 BENs furnished from seven different suppliers were selected. In Glera wine, BENs showed a limited removal of RF even at the highest dosage (on average, $28 \%$ of reduction at $80 \mathrm{~g} / \mathrm{hL}$ ) in accordance with the data reported by Fracassetti and colleagues (2017) when testing a calcic BEN at $100 \mathrm{~g} / \mathrm{hL}$ in Chardonnay wine. Interestingly, the treatment with SODCAL BEN (BENT5) at $80 \mathrm{~g} / \mathrm{hL}$ led to a sensible reduction, corresponding to about $60 \%$, of RF (Fig. 2). Considering that white wines present a mean RF content of $115 \mu \mathrm{g} / \mathrm{L}$ (Cataldi et al., 2002), this is the only BEN treatment that assured to decrease RF content below $50 \mu \mathrm{g} / \mathrm{L}$, which is considered the threshold for light-struck taste risk (Fracassetti et al., 2019). Nevertheless, several cases of white wine in which concentration of RF overcame 151 $\mu \mathrm{g} / \mathrm{L}$ have been reported (Ournac, 1968; Pilcher, 1996), and it should be taken into account that high dosages of BEN could lead to severe side effects, that is, wine aroma depletion (Lambri et al., 2012; Lira et al., 2015).

Statistical analysis evidenced a significant difference among BENs only at $60 \mathrm{~g} / \mathrm{hL}$, and BENT5 confirmed to be the most efficient BEN. In two cases, BENT5 and BENT6, a statistically significant effect of dosage was registered (Figure 2). As also reported by Fracassetti and colleagues (2017), no evidence of different responses was observed between CAL and SOD. The statistical analysis revealed no significant correlation $(r=-0.33, P=0.328)$ between the percentage of removed RF at the highest BEN dosage and the protein removal curve slope, reinforcing the idea that protein and RF are linked to BEN surfaces through different mechanisms. BENs are known to link molecules by means of three different mechanisms: the first involves dipole bindings, the second is based on hydrogen bonding through the water bridge mechanism, and the third is based on Van der Waals forces (Luckham and Rossi, 1999). Probably, the chemical structure of RF, characterized by low polarity, induces the 


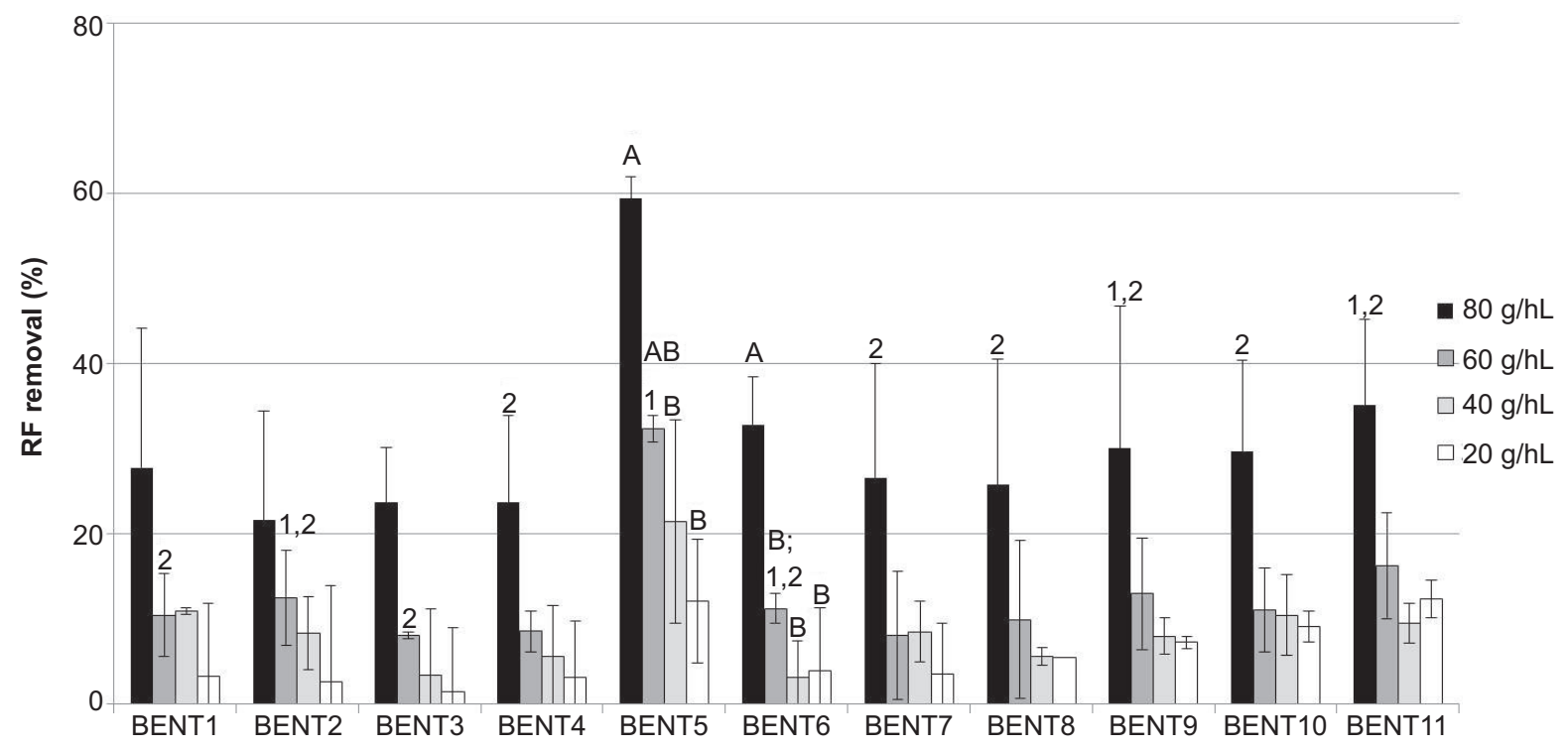

Figure 2. Riboflavin removal by bentonites. Mean values and standard deviation of two replicates are presented. Statistical differences between doses of bentonite are expressed by capital letters, while differences between bentonites at the same dosage are expressed by numbers (Tukey test, $P<0.05$ ).

establishment of low polar bonds belonging to two latter types (Kasimova et al., 2019).

\section{Charcoal's decolorizing capacity}

Active CHAs are commonly used in oenology to reduce organoleptic fault because of phenolic off-odors (Lisanti et al., 2017) as well as fining agents to correct color intensity of white wines obtained by the vinification of red grapes. Their application depends on physical properties of $\mathrm{CHA}$, in particular on the pore size, which strongly affects CHA permeability through molecular size exclusion. In fact, decolorizing CHAs are characterized by $20-500 \AA$ macropores, while deodorizing CHAs show a dominance of small pores (Yahya et al., 2015). Resolution Oeno 7/2007 (OIV, 2007) categorizes CHAs into the two groups based on the percentage of enocyanin removed from a model wine (decolorizing power). In particular, CHAs are assigned to DEC group if they are able to remove more than $40 \%$ of initial enocyanin, while they are recognized as DEO if the removed enocyanin is less than $40 \%$. The decolorizing power of 11 selected CHAs was analyzed.

For all CHAs, decolorizing power test confirmed the category assignment declared in the technical datasheets. Four CHAs belonged to DEO, namely CHA3, CHA4, CHA8, and CHA11, while six CHAs were clearly assigned to DEC (CHA1, CHA5, CHA6, CHA7, CHA9, and CHA10; Figure 3). The ambiguous case of $\mathrm{CHA} 2$

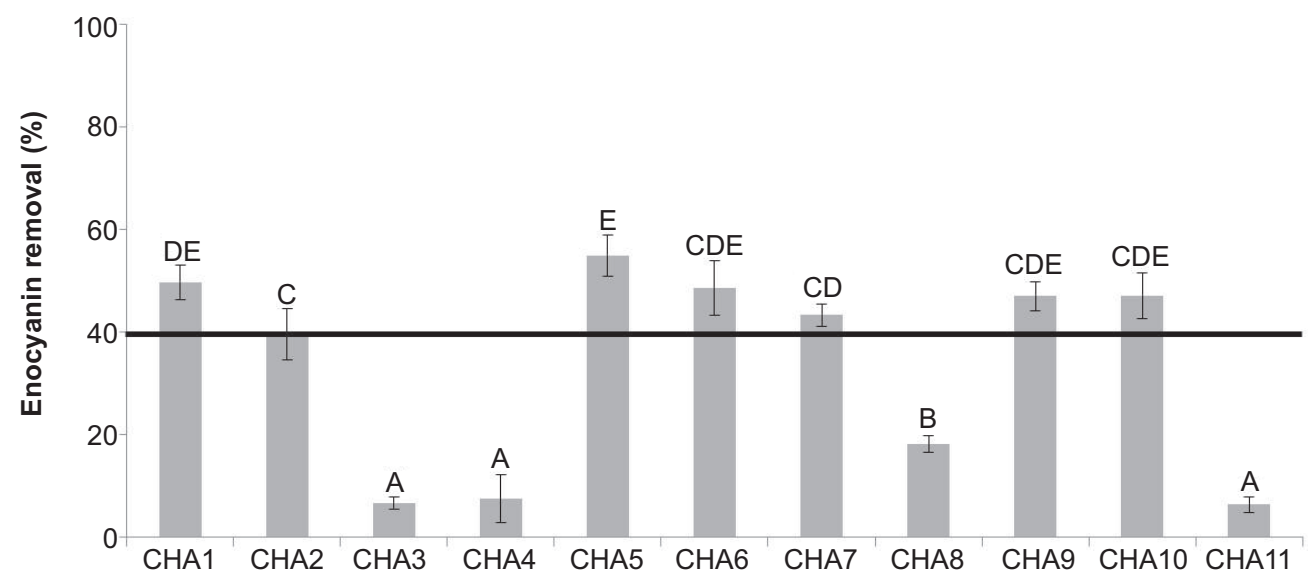

Figure 3. Percentage values of enocyanin removal. Mean values and standard deviations are presented. Each test was repeated for three times. Different capital letters identify significantly different groups $(P<0.05)$ according to post hoc Tukey test. Line corresponds to OIV threshold. 
that reduced $40 \%$ of enocyanin content was ascribed to DEC in accordance with the statistical analysis, which grouped CHA2 with CHA6, CHA7, CHA9, and CHA10. Statistical analysis evidenced significant differences between samples $\left(F_{(10,22)}=108.8, P<0.01\right)$ and allowed to differentiate decolorizing power ability even inside the two categories. For example, different from the other DEO, CHA8 revealed a singularly higher decolorizing power, which confirmed the specific supplier declaration of presence of high mesopores. Among DEC, CHA5 achieved the highest percentage of subtraction (almost $55 \%$; Figure 3).

\section{Charcoal's riboflavin removal in white wine}

In a recent study, CHA was recognized as the best fining agent for removal of RF (Fracassetti et al., 2017). Nevertheless, CHA should be carefully used in order to avoid undesirable effects on wine, such as depletion of color and flavor. Therefore, in this work five dosages of low-range CHA (between $0.5 \mathrm{~g} / \mathrm{hL}$ and $10 \mathrm{~g} / \mathrm{hL}$ ) have been used for comparison. In a preliminary test performed with different contact periods, CHAs showed the best vitamin removal property after $24 \mathrm{~h}$ of contact (Figure SI-1); therefore, the CHA samples are compared after $24 \mathrm{~h}$. In white wine, the results evidenced that DEC have a better performance than DEO at all tested doses, achieving about $90 \%$ of RF removal (Figure SI-2). As reported for other absorption kinetics, RF showed a positive but nonlinear trend of reduction with respect to CHA concentration increment (Ribéreau-Gayon et al., 2006). Differences between decolorizing and deodorizing CHAs were statistically significant at all doses, and drop in doses corresponded to a progressive decrease in differences between average of categories (Figure SI-2). As indicated by Fracassetti et al. (2017), in real wine even the highest CHA concentration didn't allow the complete removal of RF. In fact, Fracassetti et al. (2017) reported that after $24 \mathrm{~h}$ of contact a large-pore CHA was able to remove $100 \% \mathrm{RF}$ at 5 and $10 \mathrm{~g} / \mathrm{hL}$ in a model wine, while it reached only $58 \%$ and $71 \%$ of RF removal in Chardonnay wine. When compared with Fracassetti et al. (2017), the decolorizing CHAs studied in the present work showed higher RF removal capacity in real wine. This phenomenon probably depends on differences in wine compositions because of grape varieties and winemaking processes.

Recently, it has been demonstrated that decreasing the final RF concentration below $50 \mu \mathrm{g} / \mathrm{L}$ drastically reduced the risk of light-struck development (Fracassetti et al., 2019), and therefore this concentration was chosen as a threshold for the evaluation of efficacy of CHAs. DEC assured sufficient removal of RF at $10 \mathrm{~g} / \mathrm{hL}$ and $5 \mathrm{~g} / \mathrm{hL}$ (residual RF concentration of $13.58 \pm 5.24 \mu \mathrm{g} / \mathrm{L}$ and $31.25 \pm 9.01 \mu \mathrm{g} / \mathrm{L}$, respectively). On the other hand, DEO permitted to achieve the threshold only after treatments with the highest doses and only with two CHAs (CHA4 and CHA8 with a residual RF of $39.61 \pm 2.80 \mu \mathrm{g} / \mathrm{L}$ and $34.95 \pm 2.49 \mu \mathrm{g} / \mathrm{L}$, respectively; Figs $4 \mathrm{a}$ and $4 \mathrm{~b})$. The percentage of RF reduction in samples treated with DEC varied between $85 \%$ and $94 \%$, with the only exception of CHA2, which is the worst color removal DEC. Among DECs, CHA5 evidenced the best performance, reducing the RF value from $104 \mu \mathrm{g} / \mathrm{L}$ to $5.71 \mu \mathrm{g} / \mathrm{L}$. It could be observed that CHAs demonstrated interesting variation in their efficiency depending on the dosage. CHA5 showed a reduction of only $10 \%$, passing from $10 \mathrm{~g} / \mathrm{hL}$ to $5 \mathrm{~g} / \mathrm{hL}$, other two CHAs, namely CHA1 and CHA10, showed a reduction of about $15 \%$, while CHA6, CHA7, and CHA9 showed a marked reduction (higher than $20 \%$ ). CHA2 lost $18 \%$ of its removal ability passing from $10 \mathrm{~g} / \mathrm{hL}$ to $5 \mathrm{~g} / \mathrm{hL}$. This resulted in a greater difference registered among DEC at $5 \mathrm{~g} / \mathrm{hL}$, which showed an RF removal varying between $63.2 \%$ and $88.6 \%$, corresponding to $41-15 \mu \mathrm{g} / \mathrm{L}$ of residual RF (Figure $4 \mathrm{a}$ ).

DEO could be divided into two subcategories. CHA4 and CHA8 achieved a maximum RF reduction of about $65 \%$. Differently, CHA3 and CHA11 evidenced a very low RF removal, without exceeding $25 \%$ even at $10 \mathrm{~g} / \mathrm{hL}$, leaving a residual vitamin concentration of $82.78 \pm 5.63 \mu \mathrm{g} / \mathrm{L}$ and $79.15 \pm 0.21 \mu \mathrm{g} / \mathrm{L}$, respectively (Figure $4 \mathrm{~b}$ ) in the investigated white wine. Differences in RF adsorption could be attributed to specific surface availability between the two categories as well as within DEO. It is well known that the main difference between DEC and DEO lies in pore size (Yahya et al., 2015). Even if mesopores and micropores seem to be the main contributors in CHA's removal power, by extending the surface area, macropores could represent an indispensable way for large molecules to achieve internal surfaces. Recently, it has been demonstrated that reduction in large-size pores affects CHA affinity toward methylene green, a cationic dye showing high similarity to RF molecule structure (Tran et al., 2017). Most likely, pore configuration could also affect RF permeability and consequently its removal, confirming the previous finding of having close relationship between pore size and RF permeability (Kisler et al., 2001). Color intensity of white wine was evaluated after treating with $10 \mathrm{~g} / \mathrm{hL}$ of CHA in order to quantify color depletion (CD) at $420 \mathrm{~nm}$. Color depletion significantly differed between CHA categories $\left(F_{(1,31)}=40.42, P<0.05\right.$; data not shown); on average, DEO removed $5 \%$, while DEC removed $8 \%$ of color. Pearson's correlation analysis between percentage of RF removal and color depletion at $10 \mathrm{~g} / \mathrm{hL}$ revealed a positively significant correlation $(r=0.77, P<0.05)$, which indicated that RF and flavan-3-ols/flavonoids have similar interaction with CHA. Concerning this, Gogoi and colleagues (2010) suggested that the catechin sequestration by activated carbon depended on external 


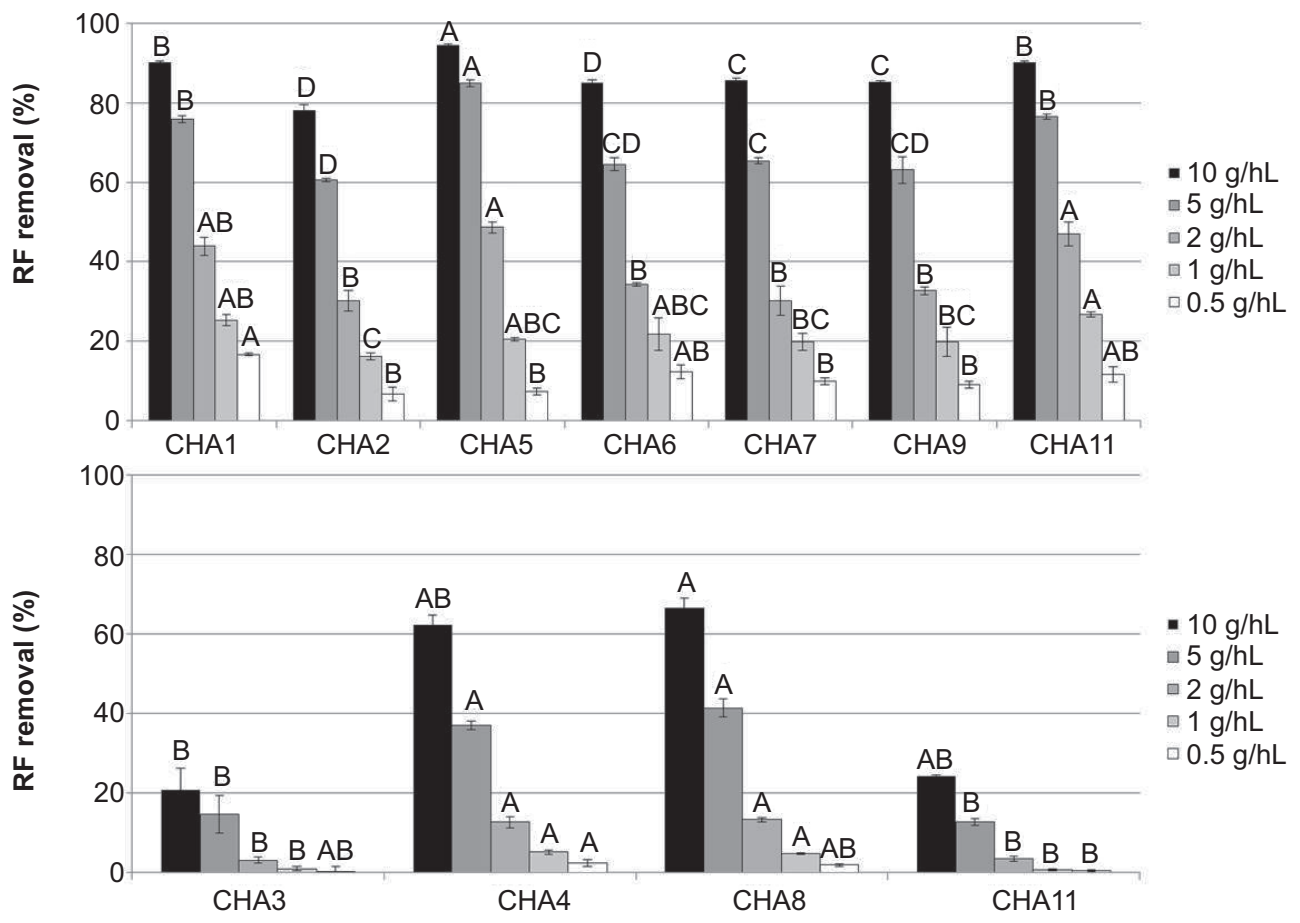

Figure 4. Removal of riboflavin in white wine. (a) Wine treated with decolorizing CHAs. Different capital letters identify statistically significant differences within carbon according to post hoc Games-Howell test $(\mathrm{Cl}=0.95$, dosage $10 \mathrm{~g} / \mathrm{hL}$ ) and Tukey test $(P>0.05$, other doses). (b) Wine treated with deodorizing CHAs. Different capital letters identify statistically significant differences within carbon according to post hoc Dunn test $(C \mathrm{Cl}=0.95$, dose: $10 \mathrm{~g} / \mathrm{hL}$ and $0.5 \mathrm{~g} / \mathrm{hL})$ and Tukey test $(P>0.05$, other doses). Mean values and standard deviations of three replications are expressed.

physicochemical parameters, for example, $\mathrm{pH}$ and competing compounds present in the solution that could interfere in the solute-sorbent association. This linkage was supposed to occur as an equilibrium between the hydrogen bonding (less important in the water environment because of high number of water hydrogen bonds) and the $\pi$-electron interaction between phenol ring and carbon backbone, which directly determines the bond strength.

\section{Charcoal's RF removal in red wine}

Quantity of RF in wine directly depends on grape variety and winemaking process (Cataldi et al., 2002). On average, red wines revealed higher vitamin content with respect to both white and rosè wines. Although the lightstruck phenomenon is not relevant in red wines, it has been demonstrated that RF-mediated oxidation could play a role in degradation of anthocyanins (Kim et al., 2010). Moreover, CHAs are more often used in fining of red wine (Lisanti et al., 2008). Therefore, CHA's ability to remove RF in red wine is of particular interest. As before, RF quantification was performed after $24 \mathrm{~h}$ of treatment, samples were kept in dark condition, and five dosages were tested. As before, DEC resulted in a higher RF removal capacity than DEO at all selected concentrations (Figure SI-3). The best performance was shown by DEC at $10 \mathrm{~g} / \mathrm{hL}$ with a significant difference from $\operatorname{DEO}\left(F_{(1,32)}=\right.$ 53.82, $P<0.05)$. In general, CHAs evidenced a reduced ability of RF removal in red wine in comparison to white wine; in fact, DEC registered less than $25 \%$ of RF removal at the highest concentration. This effect could depend on other wine components which interfere in the RF-CHA interaction. These compounds likely belong to phenolics, which have been studied for their high affinity to CHA (Dąbrowski et al., 2005). Deodorizing CHAs revealed no RF removal capacity in red wine; on the contrary, they seem to display a slight RF protection, as the final RF content in the treated samples was slightly higher than in the control (Figure SI-3). It is widely reported that spontaneous degradation of RF occurs during the first few hours of opening of bottle (Mattivi et al., 2000) and that this phenomenon is accelerated in organic solvents (Sheraz et al., 2014). Even by keeping the samples in the dark, a slight RF degradation occurred during the treatment; however, the presence of DEO seemed to prevent this degradation, as the RF content was greater at higher CHA concentrations. It can be assumed that the same RF degradation occurred in all the samples; although in DEC-treated samples the RF removal masked this effect, in DEO-treated samples the removal power was too low. 


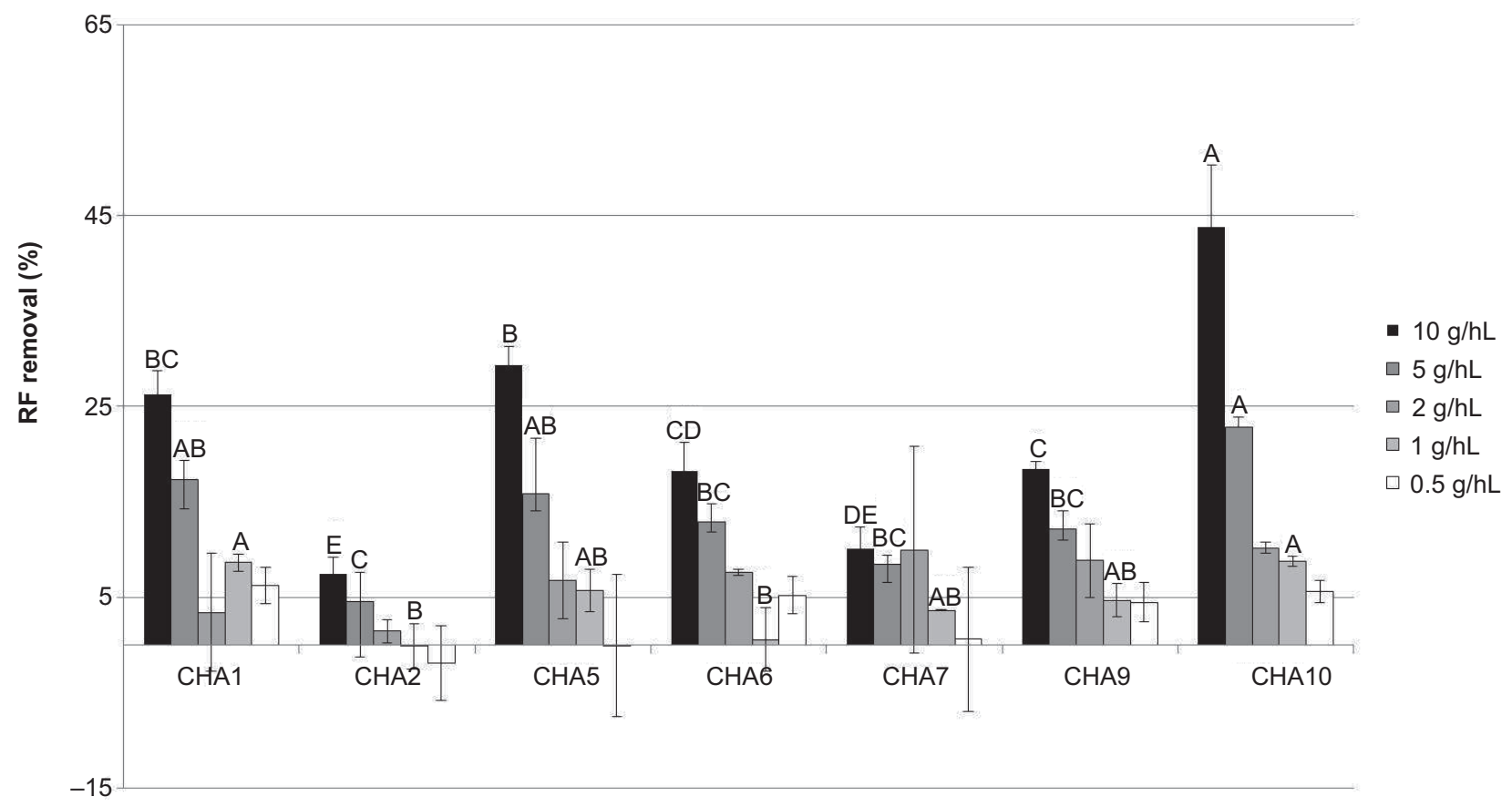

Figure 5. Riboflavin removal of decolorizing CHAs in red wine. Different capital letters identify statistically significant differences within DEC according to post hoc Tukey test $(P>0.05)$ at the dosages of $10 \mathrm{~g} / \mathrm{hL}, 5 \mathrm{~g} / \mathrm{hL}$, and $1 \mathrm{~g} / \mathrm{hL}$. Mean values and standard deviations of three replications are expressed.

Even in DEO-treated samples, differences between categories were statistically significant at all dosages.

The analyses of individual CHAs belonging to DEC group revealed strong differences in their behaviors. In particular, CHA10 was identified as the best one for RF removal. In fact, it is the only one that reduced the RF value by $43 \%$ at $10 \mathrm{~g} / \mathrm{hL}$ (corresponding to a final concentration of $77.96 \pm 9.11 \mu \mathrm{g} / \mathrm{L}$ in treated wine; Figure 5). Considering the initial RF concentration of $138 \mu \mathrm{g} / \mathrm{L}$, it means that about $60 \mu \mathrm{g} / \mathrm{L}$ was removed, similar to the depletion recorded in white wine at $5 \mathrm{~g} / \mathrm{hL}$. Two CHAs, namely CHA1 and CHA5, exhibited limited ability, reaching a little more than $25 \%$ of removal (Figure 5). In all other cases, the RF sequestering was very low. Color depletion at $10 \mathrm{~g} / \mathrm{hL}$ significantly differed between CHA categories $\left(F_{(1,31)}=85.19, P<0.05\right)$; DEO removed on average $2 \%$, while DEC removed $9 \%$ of color intensity. The correlation between percentage of removed RF and color depletion at $10 \mathrm{~g} / \mathrm{hL}$ highlighted a positively significant correlation $(r=0.88, P<0.05)$. This suggests that the interaction between RF and polyphenols with CHA is characterized by a similar binding mechanism. In a dynamic equilibrium, this mechanism depends on the ionic strength (and $\mathrm{pH}$ ) of the solvent that probably involved electron donor-acceptor interactions between the aromatic phenolic ring and the surface oxygens, dispersion effect between the aromatic phenolic ring and the $\pi$ electrons of the graphitic structure, and, if ions are present, then electrostatic attraction and repulsion (Dạbrowski et al., 2005).

\section{Conclusion}

This work explored the potential of commercial BENs and active CHAs in lowering of RF in real wines. BENs showed a reduced ability to sequester $\mathrm{RF}$ which appeared independent from their shied cation nature, and thus from their swelling properties. Among 11 different commercial BENs, only a sodic-calcic BEN (BENT5) revealed an interesting higher ability in RF removal. This work represents the first study in which a sodic-calcic BEN has been tested for this purpose. The future studies would define whether SOD-CAL matrices could play a role as $\mathrm{RF}$ removal agents. On the other side, activated CHAs confirmed their high attitude to remove RF, which for the first time was tested in both white and red wines. A great difference between deodorizing and decolorizing CHA was registered in both wines, which probably depends on CHA porosity. Additionally, in comparison to white wine, CHA RF removal was dramatically reduced in red wine. On average, decolorizing CHAs revealed $87 \%$ of RF removal in Glera wine to $22 \%$ in Wildbacher wine. This phenomenon has been attributed to complex interactions between $\mathrm{CHA}$ and wine phenols. Phenolic acids, 
flavan-3-ols, and flavonoids could establish $\Lambda$-electron interactions between phenolic ring and the active binding sites of $\mathrm{CHA}$, and therefore could represent direct $\mathrm{RF}$ competitors. This phenomenon could also explain different RF removal efficiency of CHA fining in real wines (present work) compared to a model wine (Fracassetti et al., 2017). To date, it is not clear whether the phenolic compounds belonging to different classes have the same effects on CHA-RF interaction.

\section{Acknowledgment}

Authors would like to thank the School of Oenology of Conegliano Isiss 'G.B. Cerletti' and Azienda Agricola ‘Conte Collalto' S.A.R.L for providing treated wines.

\section{References}

Achaerandio, I., Pachova, V., Güell, C. and López, F. 2001. Protein adsorption by bentonite in a white wine model solution: effect of protein molecular weight and ethanol concentration. Am J Enol Vitic. 52: 122-126.

Cataldi, T.R.I., Nardiello, D., Scrano, L. and Scopa, A. 2002. Assay of riboflavin in sample wines by capillary zone electrophoresis and laser-induced fluorescence detection. J Agric Food Chem. 50(23): 6643-6647. https://doi.org/10.1021/jf020212a

Dạbrowski, A., Podkościelny, P., Hubicki, Z. and Barczak, M. 2005. Adsorption of phenolic compounds by activated carbon - a critical review. Chemosphere 58(8): 1049-1070. https://doi. org/10.1016/j.chemosphere.2004.09.067

Fracassetti, D., Gabrielli, M., Enncinas, J., Manara, M., Pellegrino, I. and Tirelli, A. 2017. Approaches to prevent the light-struck taste in white wine. Austral J Grape Wine Res. 23(3): 329-333. https://doi.org/10.1111/ajgw.12295

Fracassetti, D., Limbo, S., Pellegrino, L. and Tirelli, A. 2019. Lightinduced reactions of methionine and riboflavin in model wine: effects of hydrolysable tannins and sulfur dioxide. Food Chem. 298: 124952. https://doi.org/10.1016/j.foodchem.2019.124952

Gogoi, P., Dutta, N.N. and Rao, P.G. 2010. Adsorption of catechin from aqueous solutions on polymeric resins and activated carbon. Indian J Chem Technol. 17(5): 337-345.

Grant-Preece, P., Barril, C., Schmidtke, L.M., Scollary, G.R. and Clark, A.C. 2017. Light-induced changes in bottled white wine and underlying photochemical mechanisms. Crit Rev Food Sci Nutr. 57(4): 743-754. https://doi.org/10.1080/10408398.2014.919246

Jackson, R.S. 2011. Shelf life of wine. In: D. Kilcast and P. Subramaniam (Eds.) Food and Beverage Stability and Shelf Life. Woodhead, Cambridge, pp. 540-570 https://doi.org/10.1533/ 9780857092540.3.540

Jönsson, B., Åkesson, T., Jönsson, B., Meehdi, S., Janiak, J. and Wallenberg, R. 2009. Structure and forces in bentonite MX-80. SKB Technical Report, CM Gruppen, Stockholm, Sweden.

Kasimova, G.K., Astanov, S.K., Kurtaliev, E.N. and Nizomov, N.N. 2019. Structure of self-assembled riboflavin molecules in solutions. J Mol Struc. 1185: 107-111. https://doi.org/10.1016/j. molstruc.2019.02.084

Kim, M., Yoon, S.H., Jung, M. and Choe, E. 2010. Stability of meoru (Vitis coignetiea) anthocyanins under photochemically produced singlet oxygen by riboflavin. New Biotechnol. 27(4): 435439. https://doi.org/10.1016/j.nbt.2010.01.003

Kisler, J.M., Antje, D., Stevens, G.W. and Connor, A.J. 2001. Separation of biological molecules using mesoporous molecular sieves. Microporous Mesoporous Mater. 44-45: 769-774. https://doi.org/10.1016/S1387-1811(01)00259-1.

Lagunes, I., Vázquez-Ortega, F. and Trigos, Á. 2017. Singlet oxygen detection using red wine extracts as photosensitizers. J Food Sci. 82(9): 2051-2055. https://doi.org/10.1111/1750-3841.13815

Lambri, M., Dordoni, R., Silva, A. and de Faveri, D.M. 2012. Comparing the impact of bentonite addition for both must clarification and wine fining on the chemical profile of wine from Chambave Muscat grapes. Int J Food Sci. Technol. 47(1): 1-12. https://doi.org/10.1111/j.1365-2621.2011.02800.x

Lira, E., Rodríguez-Bencomo, J.J., Salazar, F.N., Orriols, I., Fornos, D. and López, F. 2015. Impact of bentonite additions during vinification on protein stability and volatile compounds of Albariño wines. J. Agric Food Chem. 63(11): 3004-3011. https://doi. org/10.1021/acs.jafc.5b00993

Lisanti, M.T., Gambuti, A., Genovese, A., Piombino, P. and Moio, L. 2017. Treatment by fining agents of red wine affected by phenolic off-odour. Eur. Food Res. Technol. 243(3): 501-510. https:// doi.org/10.1007/s00217-016-2763-4

Lisanti, M.T., Piombino, P., Gambuti, A., Genovese, A., Siani, V.L. and Moio, L. 2008. Analytical evaluation of remedial treatments for red and white wines contaminated by volatile phenols. Bulletin de l'OIV (Organisation Internationale de la Vigne et du Vin), 81: 45-55.

Luckham, P.F. and Rossi, S. 1999. Colloidal and rheological properties of bentonite suspensions. Adv. Colloid Interface Sci. 82(1): 43-92. https://doi.org/10.1016/S0001-8686(99)00005-6

Marangon, M., Van Sluyter, S.C., Neilson, K.A., Chan, C., Haynes, P.A., Waters, E.J. and Falconer, R.J. 2011. Roles of grape thaumatin-like protein and chitinase in white wine haze formation. J. Agric. Food Chem. 59(2): 733-740. https://doi.org/10.1021/ jf1038234

Mattivi, F., Monetti, A., Vrhovšek, U., Tonon, D. and AndrésLacueva, C. 2000. High-performance liquid chromatographic determination of the riboflavin concentration in white wines for predicting their resistance to light. J. Chromatogr A. 888:121127. https://doi.org/10.1016/S0021-9673(00)00561-6

Ournac, A. 1968. Riboflavine pendant la fermentation du jus de raisin et la conservation du vin sur lies. Annales de Technol. Agricole. 17: 67-75.

Pilcher, U. 1996. Analisi della Riboflavina nei vini bianchi e influenza della sua concentrazione. L'enotecnico. 32: 57-62.

Ribéreau-Gayon, P., Glories, Y., Maujean, A. and Dubourdieu, D. 2006. The concept of clarity and colloidal phenomena. In: P. Ribéreau-Gayon, Y. Glories, A. Maujean and D. Dubourdieu (Eds.) Handbook of Enology The Chemistry of Wine and Stabilization and Treatments (Vol. 2). John Wiley, New York, NY, pp. 285-300. https://doi.org/10.1002/0470010398.ch9 
Sarmento, M.R., Oliveira, J.C. and Boulton, R.B. 2000. Selection of low swelling materials for protein adsorption from white wines. Int J Food Sci Technol. 35(1), 41-47. https://doi. org/10.1046/j.1365-2621.2000.00340.x

Sheraz, M.A., Kazi, S.H., Ahmed, S., Anwar, Z. and Ahmad, I. 2014. Photo, thermal and chemical degradation of riboflavin. Beilstein J Org Chem. 10, 1999-2012. https://doi.org/10.3762/bjoc.10.208

Silva, E., Barrias, P., Fuentes-Lemus, E., Tirapegui, C., Aspee, A., Carroll, L., Davies M.J. and.López-Alarcón, C. 2019. Riboflavininduced type 1 photo-oxidation of tryptophan using a high intensity 365 nm light emitting diode. Free Radical Biol Med. 131, 133-143. https://doi.org/10.1016/j.freeradbiomed.2018.11.026

The International Organization of Vine and Wine (OIV). 2007. Carbon (oenological). OENO 7/2007. Available online: https:// www.oiv.int/public/medias/4063/e-coei-1-charbo.pdf (accessed on 20.09.19).
The International Organization of Vine and Wine (OIV). 2011. Bentonites. OENO 11/2003, OENO 441/2011. Available online: https://www.oiv.int/public/medias/4055/e-coei-1-benton.pdf (accessed on 05.06.19).

Tran, H.N., Wang, Y.F., You, S.J. and Chao, H.P. 2017. Insights into the mechanism of cationic dye adsorption on activated charcoal: the importance of $\Pi-\Pi$ interactions. Process Safety Environ. Protection. 107, 168-180. https://doi.org/10.1016/j. psep.2017.02.010

Yahya, M.A., Al-Qodah, Z. and Ngah, C.W.Z. 2015. Agricultural biowaste materials as potential sustainable precursors used for activated carbon production: a review. Renewable Sustain. Energy Rev. 46, 218-235. https://doi.org/10.1016/j.rser.2015.02.051 


\section{Supplementary information}

\section{Removal of Riboflavin by Commercial Bentonites and Charcoals in White and Red Wines}

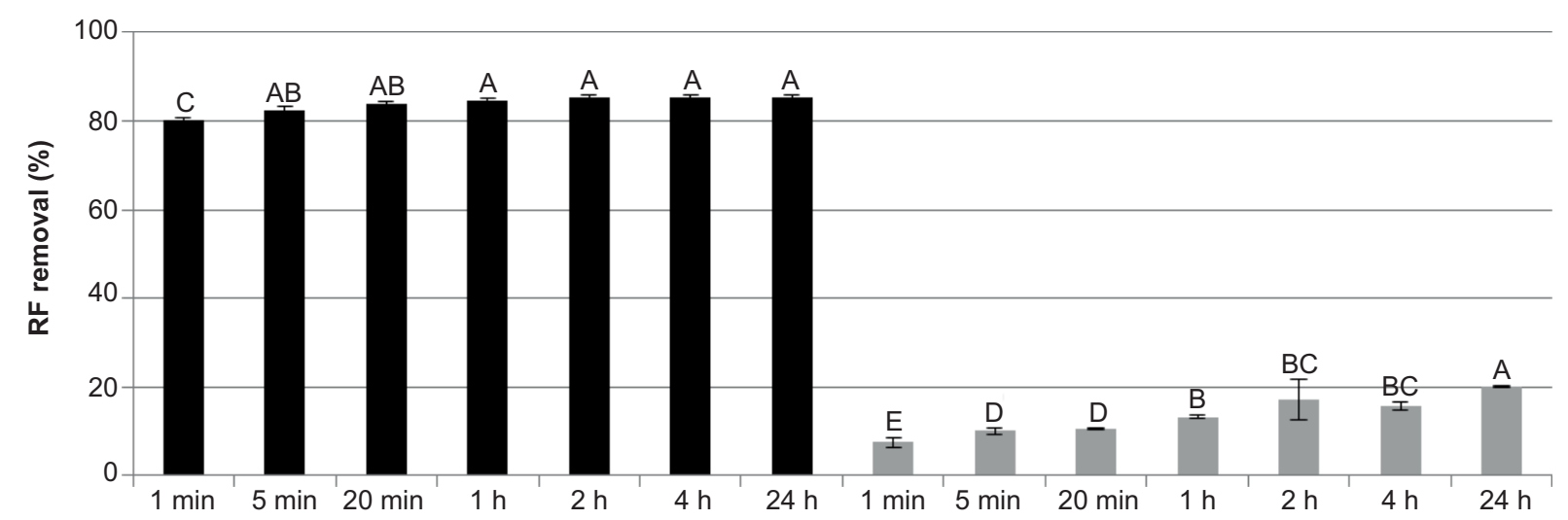

Figure SI-1. Trend of removal of riboflavin with CHA5 and CHA3 in white wine. Mean values and standard deviations are expressed. Each test was repeated for three times. Black: decolorizing CHA (CHA5), and gray: deodorizing CHA (CHA3). Different capital letters identify statistically significant differences within category according to Tukey test $(P<0.05)$.

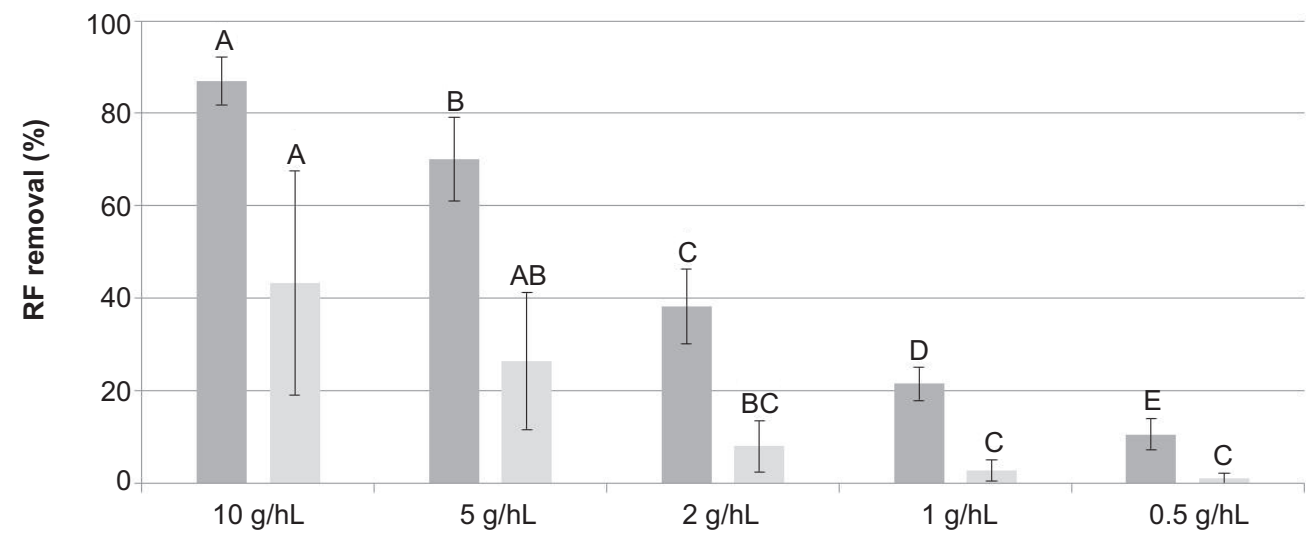

Figure SI-2. Comparison of removal of riboflavin with CHAs in white wine. Mean values and standard deviations are expressed. Each test was repeated for three times. Gray: decolorizing CHA, and light gray: deodorizing CHA. Different capital letters identify statistical significant differences within categories according to post hoc Dunn's test $(\mathrm{Cl}=0.95)$. $\mathrm{Cl}$ : Color intensity.

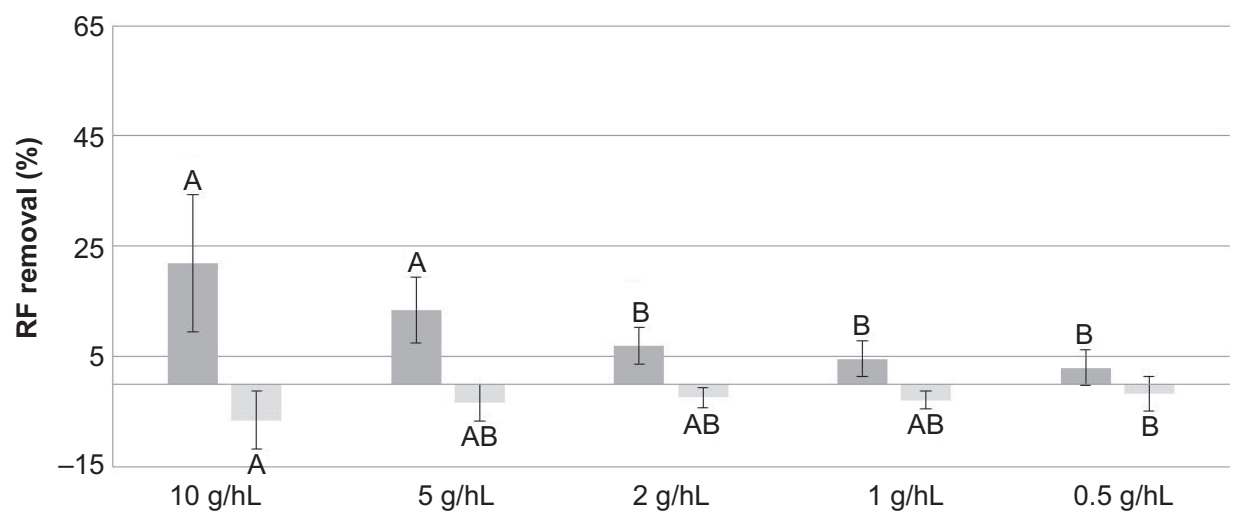

Figure SI-3. Comparison of removal of riboflavin with CHA in red wine. Mean values and standard deviations are expressed. Each test was repeated for three times. Gray: decolorizing CHA, and light gray: deodorizing CHA. Different capital letters identify statistically significant differences within category according to Dunn's test $(\mathrm{Cl}=0.95)$ and Tukey test $(\mathrm{P}<0.05)$ respectively. Cl: Color intensity. 